\title{
Monitoring Of Engine Lubrication Using Acoustic Emission Technology
}

\author{
M. Fadhlan ${ }^{1}$, M. Yusof ${ }^{2}$, A. Solahuddin ${ }^{3}$ \\ ${ }^{123}$ Faculty of Mechanical Engineering, Universiti Malaysia Pahang, Malaysia \\ Email:fadhlan@ump.edu.my
}

\begin{abstract}
This research presents the application of Acoustic Emission (AE) sensor to explore the feasibility of an AE signal in the process of monitoring the engine oil viscosity on different condition of mileage during the engine operation. The viscosity experiment was performed in a prior stage of the experiment using four samples of SAE $5 W-30$ engine oil with the different condition of mileage. On the next occasion, the AE signal was acquired on three cylinders of a four-stroke gasoline engine with a cooling water system which operates using the previous lubricant sample. In this experiment, the AE sensor was bonded on the outside of the engine block and located at the oil filter and oil sump location. It was found that the AE energy value is capable of determining the variant of the engine oil viscosity. The results from this project show that via AE technology proved to be feasible for the development of a real-time lubricant condition monitoring which was believed to be a new technology in the automotive industry.
\end{abstract}

Keywords acoustic emission, engine lubricant, monitoring system.

Paper type Research paper

\section{INTRODUCTION (HEADING 1)}

Lubricant plays an important role in internal engine combustion either on gasoline or diesel engine. The lubricant constantly performs as an anti-friction and a heat absorbing medium [1]. The lubricant functions to smoothen the operation of an engine and also reduce the increase of temperature during engine operation. This is to prevent the engine component from tear and wear. Two important factors needed to be emphasized, which is to maintain the quality of engine oil and to monitor the condition of the engine oil during operation of the engine. Engine oil plays an important role regarding performance and engine life span.

Short intervals of engine oil changing caused an increase in maintenance cost. In contrast, long intervals cause the rise of increasing engine wear and even engine damage [2]. In most cases of engine oil changing, typically it would be performed according to mileage or calendar schedules that are based on average data for a wide variety of vehicles [3]. However, until now, there is no proving that these practices are the most efficient and economical.

According to the Inayatullah et al., 2011 [4], most manufacturers recommend a change of engine oil at intervals $5000 \mathrm{~km}$ until $10000 \mathrm{~km}$ or three months until six months, which is depending ever earlier in a situation of the normal driving condition. Contrasting to this, manufacturers differ in their recommendations of the duration for the change of the engine oil and on the other hand, the definition of normal driving condition is not standardized.

Measurement of the viscosity of engine oil is carried out by carrying out an oil analysis that involves laboratory analysis. Oil analysis is one of the methods that can be used to measure engine oil viscosity directly. The rheology viscometer equipment was used for the oil analysis. Nonetheless, this method can be used only on engines that are not working. One of the major disadvantages of $\mathrm{AE}$ is because of severe attenuation across interfaces and rapid attenuation of $\mathrm{AE}$ in liquids and gases. Alternatively, the major advantage of $\mathrm{AE}$ is the ability of onset loss detection of mechanical integrity [5]. Due to the problem-related coordination, the AE method with the propagation of elastic waves that run at the frequency from $0.1 \mathrm{MHz}$ to $1 \mathrm{MHz}$ is appropriate to be used to monitor the viscosity of the engine oil. Both elastic and stress waves generated within, or on the surface of a material by certain vital processes that define friction, wear and tear in the form of distortions and microfractures [6]. Stress Wave Analysis (SWA) is the study of propagating waves mentioned which is possible to be conducted on the surface of the material via an appropriate transducer and acquisition system [7]. AE means the stress and elastic waves inside a material which is generated by the swift release of local instabilities.

The variability or the source mechanisms of $\mathrm{AE}$ can be divided into four major groups namely dislocation movements, phase transformations, friction mechanisms, crack formation and extension [8]. Consequently, through the estimation of the AE activity, some insights can be gained on the performance of either solid with solid or solid with the fluid of the interrelating materials in locations which can be excessive for other monitoring techniques. 
Since past decades, the development of a condition monitoring system had received greater attention from the researchers and is also widely developed in the industry. This is because it can provide significant information on early faulty or failure phenomenon. Among the methods used to develop condition monitoring study, the acoustic emission (AE) technology was one of the useful methods in the reciprocating monitoring machine either in term of faults and for running conditions.

According to [4], AE method was suitable to be used to the monitor viscosity of engine oil due to the ability of an elastic wave to propagate at the frequency from $0.1 \mathrm{MHz}$ to $1 \mathrm{MHz}$. Bustles Acoustic techniques have been widely used in the oil industry and can produce effective results. Based on the past literature, AE technology was as significantly proven to be used condition monitoring tool in an internal combustion engine. Among them AE technology had been applied to monitor the gear systems [5], the fuel injector fault [9], fuel injection behavior [10], various aspects in the combustion process [11], engine noise [12] and the damage on the exhaust valve [13]. Online monitoring of engine oil quality [14]. According to [4], AE will be used as a technique to observe the viscosity of engine oil and also to use the AE signal application to measure the viscosity of engine oil. Engine oil plays an important role in performance and engine lifespan. Short intervals of engine oil changing caused an increase in maintenance cost. In contrast, long intervals cause the rise of increasing engine wear and even engine damage [2]. In most cases of engine oil changing, typically it would be performed according to mileage or calendar schedules based on average data for a wide variety of vehicles [3]. However, there is no proving that these practices are the most efficient and economical. Based on [4], most manufacturers recommend a change of engine oil at intervals $5000 \mathrm{~km}$ until $10000 \mathrm{~km}$ or three months until six months, which is depending ever earlier in a situation of the normal driving condition. Contrasting to this, manufacturers differ in their recommendations of the duration for the change of the engine oil and the other hand, the definition of normal driving condition is not standardized.

\section{Engine Lubricant}

Lubrication plays a key role in the life span of an engine. Changing engine oil will provide a longer life span for the engine components. Without oil, an engine would overheat and stop instantaneously. The three basic details about engine lubrication that will be discussed are the beginning of engine lubrication, the makeup of the oil and oil breakdowns.

Engine lubrication begins in a repeating process. The process starts with a sump or commonly known as an oil pan in an internal combustion engine. Next, the oil pump pulls the oil from a sump to the filter through a strainer. Then the oil is pumped through to all the components of the engine. Because of the gravity, the oil is pulled back again into the sump.

Generally, engine oil which is formulated consists of two components, the additives oil, and the base oil. Depending on the formulation and application, the range of total volume additives in the engine oil varies between 20 to 30 presents. The additives increase the base oil properties. The typical additive is included with a detergent and a dispersant. Most vehicle engines use multigrade oil because the oil has an additive called viscosity index (VI) improvers. Viscosity index improvers is a long chain of organic molecules that change shape as the temperature changes as a reference during cold or hot environments. The molecules will be tightly bounded in a cold environment, whereas during heat environment this molecule begins to stretch out. This condition explains how engine oil is made up. Oil breakdowns always occur due to engine overheating, additive shearing and contamination process. Over time oil viscosity at operating temperature will be decreased, caused by fuel contaminant and sheared down on viscosity index improvers [15].

Engine oil or commonly called as motor oil is lubrication for components that are used in an internal combustion engine. Almost all components in this engine are made from steel or alloy which moves during engine operation. These movements produce high pressure and high heat which cause friction. Thereby friction will affect the wear of components since that is the function of engine oil lubrication. Engine oil is produced from petroleum chemical compounds and nonpetroleum synthesis substance which contains a percentage of fuels high on carbon and hydrogen. To improve the performance of engine oil, other substances such as esters and additives are needed to modify by mixing.

Most of the engine oil is made from molecular weight hydrocarbons from crude oil which is extracted from the seabed. Normally engine oil contains hydrocarbons with a value of between 18 until 34 carbon atoms per molecule. The engine oil viscosity that is high is caused by carbon content per high molecule. The ability to maintain a lubricating layer between the moving engine's components is the main functions of engine oil.

\section{Acoustic Emission}

Generally, acoustic is a study on any type of mechanical waves either in solids, liquid and gases also including in vibration, sound, ultrasound, and infrasound. Usually, the acoustic application is used in many aspects of our daily life, especially in the audio and noise industries. Acoustics are also defined through the science concerning with the production, control, transmission, reception, and sound effects. The necessity of acoustic in a sense refers to the study of sound, whereas it also reacts and generates in mediums such as water, air, and structure. On medium structure, acoustics form waves in solid and produce a stress wave which causes an elastic radiation wave.

Acoustic emission (AE) is a class of phenomena where transient elastic waves generated by the rapid release of energy from localized sources [16]. Acoustic emission (AE) is defined as a phenomenon occurred when materials whereby spontaneously elastic energy is releasing in the form of transient elastic waves or defined as a physical phenomenon that occurs when a material undergoes sudden change or localized movement and effect release of energy due to stress wave 
According to [17], the phenomenon of acoustic emission was usually generated in the frequency range of $20 \mathrm{kHz}$ to 3 $\mathrm{MHz}$ The frequency range of a sound wave is also located in the ultrasonic range by Kinsler et al., 2000. However, some of the acoustic emission phenomena exist in the lower frequency range. For example, in previous studies by James and Robert (1983), they have indicated that the frequency of acoustic emission from fractured geologic materials and composites was changed from $0.5 \mathrm{kHz}$ to $100 \mathrm{kHz}$. In metal, however, acoustic emission normally spreads in the frequency of between $100 \mathrm{kHz}$ to $2 \mathrm{MHz}$.

Engine lubrication begins in the reporting process. The process starts from the sump in an internal combustion engine. The oil pump pulls the oil from the sump to filter through a strainer. Then the oil is pumped through all components of the engine. Because of the gravity, the oil was pulled back again into the sump. AE signatures were captured at both oil filter and oil sump location and only focused on the resistance strength flow of the engine oil. This interaction will produce sound waves, which is, in this case, the medium of wave propagation is oil. In terms of lubrication flow, the oil flow characteristic such as oil shear and oil-film cavitation is a process elastohydrodynamic lubrication, which is several sources to produce AE [14]. When the viscosity increases, engine oil flows slowly. Conversely, when the viscosity decreases, engine oil flows faster.

Nowadays, AE applications are used in all areas of science and technology of materials. AE covers investigations of structural damage in repeated loading $\mathrm{AE}$ analysis of the material giving off stress. This technique is one of the nondestructive testing methods. The transducer is used to obtain the signature of acoustic emission during the formation of cracks in crack detection study. With the help of latest technology recently, it does not need another giant equipment to measure the AE signatures, just enough to have a data acquisition system which consists of a transducer, preamplifier, and software.

In general, acoustic emission is a phenomenon that commonly exists in materials. The uniqueness of this phenomenon raises the interest in the research and development of acoustic emission techniques. For basic acoustics, acoustics may be defined as a generation, transmission, and reception of vibration waves in the matter. When molecules of a liquid or solid are removed from its original alignment, the elastic restoring force will exist. Combined with the power of inertia will cause the system to take part in the oscillation and vibration automatically generates and sends an acoustic wave. AE monitoring is usually done in the presence of constant background noise. The detection threshold is normally set above the background noise. Reliable analysis of $\mathrm{AE}$ data requires the appropriate parameters derived from AE signals. Characteristics of acoustic emission normal wave such as maximum amplitude, count, RMS, energy and others.

\section{METHOD}

The purpose to measure engine oil is to determine the level of viscosity. Steps are followed to obtain readings of actual viscosity of the engine oil. Using four samples of Perodua engine oil, where one sample of the engine oil is new sample engine oil and three other samples are oil samples which already used based on the mileage and month. The viscosity of SAE 5W30 was used in this engine oil.

\section{DISCUSSION}

In this study of monitoring and assessing engine lubrication using acoustic emission technology, two conditions monitored were viscosity and AE signatures. Viscometer LVDV-111 Brookfield Rheometer was a device used to measure the viscosity of engine oil used in this experiment. The experiment consists of the same engine oil, multi-grade lubricant SAE 5W-30 sample with different mileages. Through this study, the results of viscosity need to be measured first before the samples were used to measure the AE signatures. The test was conducted on a four-stroke gasoline SOHC engine with three cylinders with a capacity of $847 \mathrm{cc}$. Tests were conducted in the semi-anechoic chamber in University Malaysia Pahang.

As mentioned earlier, the first sample of engine oil which is new oil functioned as a constant measure for viscosity. The viscosity of new oil or unused oil was at $10.6 \mathrm{cP}$, which was the value in term of dynamic (absolute) viscosity. Another sample was used oil, which was taken after three months of usage and the mileage was at $1874 \mathrm{~km}$.

The second sample engine oil had $5218 \mathrm{~km}$ of mileage and three months of usage. Finally, the third oil sample had a mileage of $7500 \mathrm{~km}$. From these three samples of used oil, the viscosity for the first sample was $10.2 \mathrm{cP}$, the second sample was $10.8 \mathrm{cP}$ and the third sample was $11.9 \mathrm{cP}$. All values of used oil were in term of dynamic (absolute) viscosity. The viscometer commonly measures viscosity in terms of dynamic (absolute) viscosity and has to be converted into kinematic viscosity. This is a requirement to get the value of centistokes.

There are four types of engine oil used. The new oil acting as a baseline has the kinematic viscosity of $12.5 \mathrm{cSt}$, the used engine oil with a mileage of $1874 \mathrm{~km}$ has $12.3 \mathrm{cSt}, 5218 \mathrm{~km}$ mileage has $12.9 \mathrm{cSt}$, and $7500 \mathrm{~km}$ mileage has 14.1 cSt of kinematic viscosity. Based on Table 1, it can be observed that the significant limitation in percentages the viscosity of sample B lies within $-1.6 \%$. On the other hand, limitation in percentages of the viscosity of sample C and sample D has shown to be within $3.2 \%$ and $12.8 \%$ respectively. Sample A, however, was set as a baseline.

Noria recommended that the limits be set in percentages. Sample B to be positioned at caution (lower) but sample C and sample D are positioned at caution (upper) and critical (upper). The viscosity data and limitation for the service oil viscosity results can be referred to Table 4.2. However, Figure 4.1 shows a chart of how viscosity monitoring should be performed, as well as the potential investigation required. 
Table 1. Result Of Viscosity

\begin{tabular}{ccccc}
\hline $\begin{array}{c}\text { Type of Engine } \\
\text { Oil }\end{array}$ & $\begin{array}{c}\text { Unused/New Oil } \\
\text { Sample A }\end{array}$ & $\begin{array}{c}\text { 3 Month and 1874 Km } \\
\text { Sample B }\end{array}$ & $\begin{array}{c}\text { Month and 5218 Km } \\
\text { Sample C }\end{array}$ & $\begin{array}{c}\text { Month and 7500 } \\
\text { Km }\end{array}$ \\
\hline Dynamic (Absolute) & 10.6 & 10.2 & 10.8 & 11.9 \\
$\begin{array}{c}\text { Viscocity (cP) } \\
\text { Convert to } \\
\text { Kinematic }\end{array}$ & 12.5 & 12.3 & 12.9 & 14.1 \\
$\begin{array}{c}\text { Viscocity (cSt) } \\
\text { Limitation in } \\
\text { Percentage }\end{array}$ & & & & \\
$(\%)$ & BASELINE & $-1.6 \%$ & $+3.2 \%$ & $+12.8 \%$ \\
\hline
\end{tabular}

Table 2. Viscosity Data And Limitation For In Service Oil Viscosity

\begin{tabular}{cc}
\hline Limit & Crankcase Oils* \\
\hline Critical (upper) & $+20 \%$ \\
Caution (upper) & $+10 \%$ \\
Caution (lower) & $-5 \%$ \\
Critical (lower) & $-10 \%$ \\
\hline
\end{tabular}

*Crankcase oil limits based on cSt @ $100^{\circ} \mathrm{C}$

Figures 2-3 shows the results of a typical analysis of waveform from two locations of the oil filter and oil sump respectively. Each graph as shown has the same pattern which was a typical AE continuous signal. The pattern of each test sample typical $\mathrm{AE}$ was not clear and also hard to recognize these types of $\mathrm{AE}$ signal by the sample.

The Figures 2-3 shows a sample of lubricant the AE Energy for both oil filter and oil sump through four sample variant of engine oil with different mileage. The new oil sample A was blue. However, the used oil, sample B which was red color had a mileage of $1874 \mathrm{~km}$, sample $\mathrm{C}$ which was green in color had a mileage of $5218 \mathrm{~km}$, and sample D which was purple had a mileage of $7500 \mathrm{~km}$. Based on Figures 4.4 and Figure 4.5, it can be observed that significant AE Energy mean value for both oil filters for test (a) of sample 1, test (b) of sample 2 and test (c) of sample 3 and oil sump at test (a) of sample 1, test (b) of sample 2 and test (c) of sample 3 had the same pattern. The higher value of AE Energy mean value was sample B, while the lowest value of AE Energy mean value was sample D. However, the AE Energy means value for used oil sample A and sample $\mathrm{C}$ was located between sample B and sample D. This shows that when the viscosity increased engine oil flow slows down and causes the AE energy to be low. This was due to the basic function of the filter itself which filters the impurities in engine oil before it is sent to the engine components. The condition refers to the location of the AE sensor on the oil filter. Besides this, the oil sump has the same pattern of AE energy mean value. This was also due to the role of oil sump itself acting as a reservoir tank of oil 

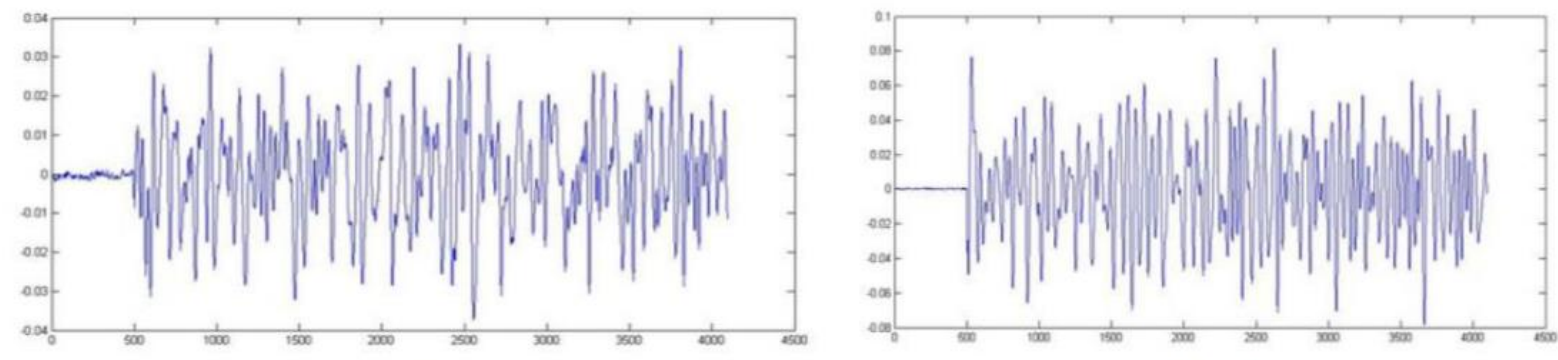

New Oil
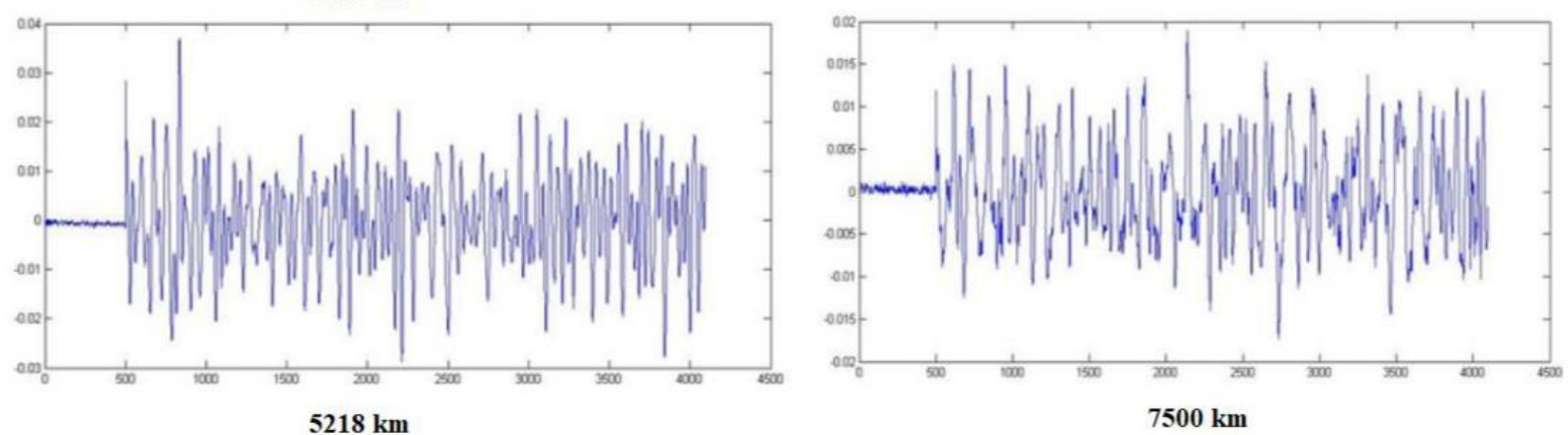

Fig. 1. Result of Oil Filter Typical Analysis.
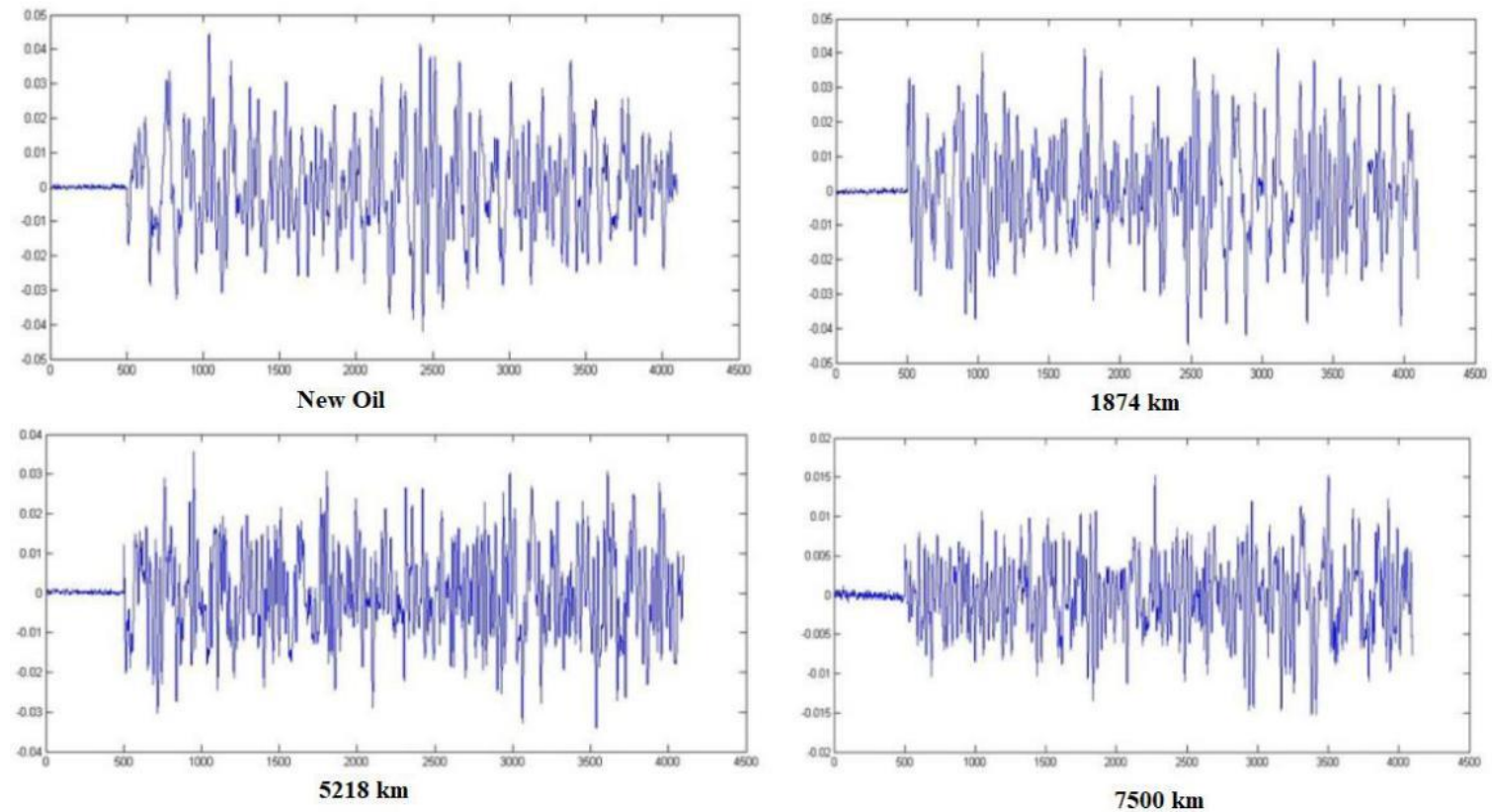

Fig. 2. The result of Oil Sump Typical Analysis

Figure 3 show AE energy vs time at oil filter The mean value for sample B is 49240 Joule, which was the highest value. Followed by sample A which was 37860 Joule, and sample C was 36700 Joule. However, the mean AE energy for sample D was 24150 Joule, which was the lowest value. The graph of oil filter for the test (b) of sample 2 shows AE energy mean value for the sample B was 52260 Joule, which was the highest value. Followed by sample A was 38900 Joule and sample C was 30870 Joule. However, the mean AE energy for sample D was 24850 Joule, which was the lowest value. The graph of oil filter for the test (c) of sample 3 shows that AE energy means value for sample B was 62830 Joule, which was the highest value. Followed by sample A which was 39060 Joule and sample C was 34340 Joule. However, the mean AE energy for sample D was 24280 Joule, which was the lowest value. Figure 4.4 shows a graph analysis result of AE Energy vs Time at the location of the oil filter 


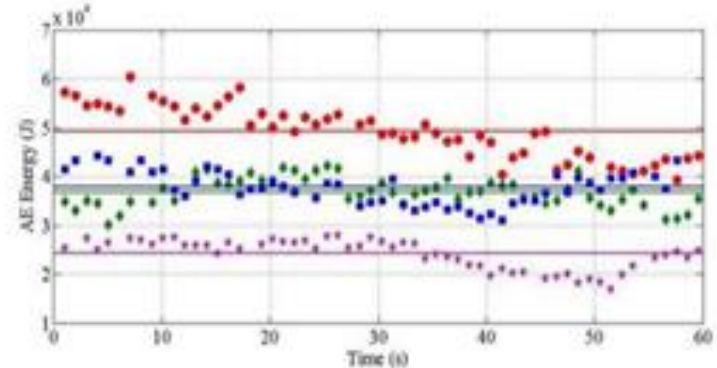

a) Sample 1

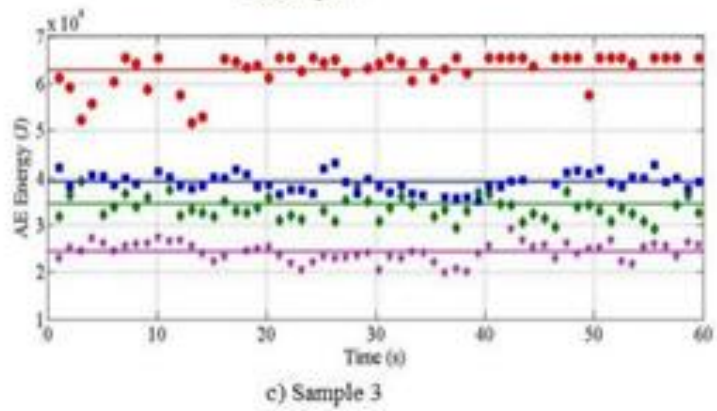

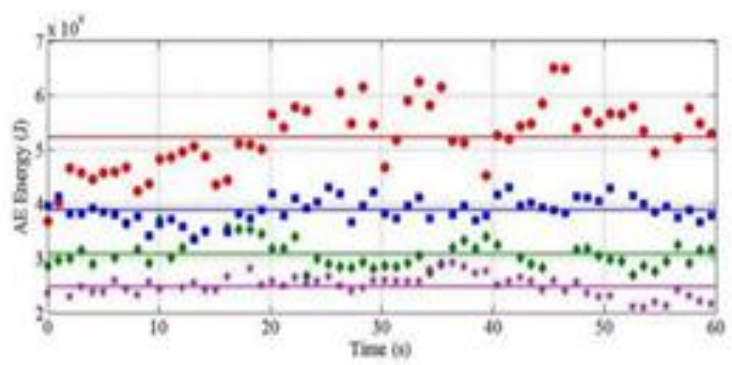

b) Sample 2

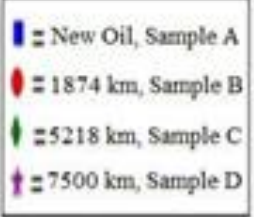

Fig. 3. Graph Analysis Results of AE Energy vs Time at Oil Filter for (a) Sample 1, (b) Sample 2 and (c) Sample 3

Figure 4 shows the graph analysis results of AE Energy vs Time at the location of the oil sump. The graph of oil sump for the test (a) of sample 1 shows the AE energy mean value for sample B was 42500 Joule, which was the highest value. Followed by sample A which was 36880 Joule and samples C was 14670 Joule. However, the mean AE energy for sample D was 12910 Joule, which was the lowest value. The graph of oil sump for the test (b) of sample 2 shows the AE energy mean value for sample B was 50020 Joule, which was the highest value. Sample A was 48850 Joule, and sample $\mathrm{C}$ was 41530 Joule. However, the mean AE energy for sample D was 16410 Joule, which was the lowest value. The graph of oil sump for the test (c) of sample 3 shows the AE energy mean value for sample B was 32480 Joule, which was the highest value. Sample A was 31860 Joule, and sample C was 24100 Joule. However, the mean AE energy for sample D was 20160 Joule, which was the lowest value.

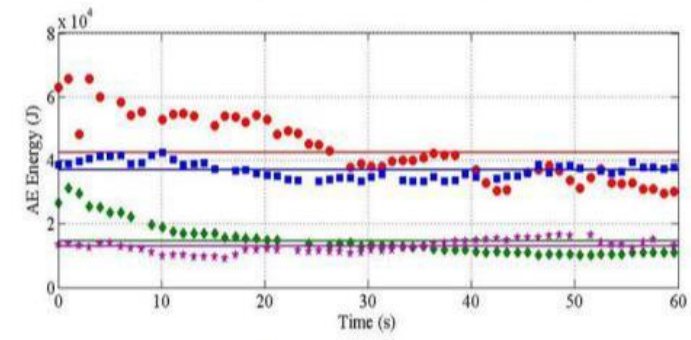

a) Sample 1

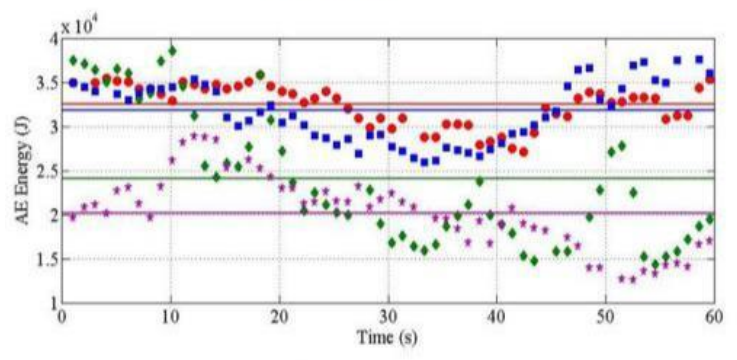

c) Sample 3

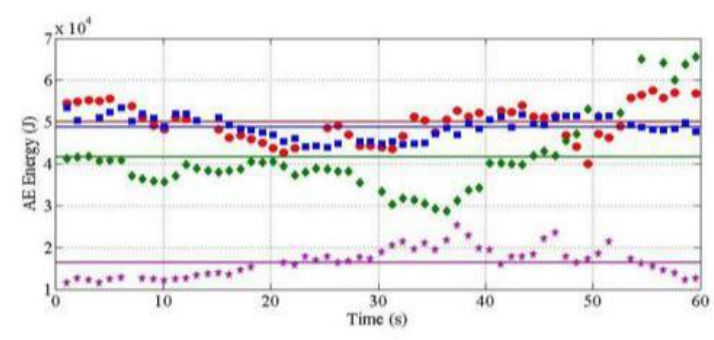

b) Sample 2

Fig. 4. Graph Analysis Results of AE Energy vs Time at Oil Filter for (a) Sample 1, (b) Sample 2 and (c) Sample 3 


\section{CONCLUSION}

A conclusion, this project can be considered successful although there are still further developments needed for future work. Implementation of a monitoring system for $\mathrm{AE}$ to assess engine oil viscosity is needed to be extended for the future. Graph signals of four samples of different lubrication condition were achieved. The first objective is to obtain an acoustic emission signal from the running engine with different lubrication conditions. Based on the condition of the typical signal, AE features were extracted from each sample of lubricants through the graph AE Energy versus Time, therefore the second objective was to analyze the differences between acoustic emission signals acquired from the running engine with different lubrication condition of the project was successfully achieved. It was clearly shown that sample A, B, C and D of AE Energy mean value decreased when the viscosity increases. Monitoring the engine lubricant viscosity required the $\mathrm{AE}$ sensor to be set at the oil filter and oil sump. In this position, AE signatures were captured and the only focus was on the resistance strength flow of the engine oil. This phenomenon of AE Energy declined due to high viscosity making it difficult for the engine oil to flow. In this project, a system was fully developed by using an $\mathrm{AE}$ sensor to monitor and assess the lubricant of engine oil viscosity. In order to make a perfect project, there are a few recommendations for any future works. One of the recommendations is the need to upgrade the operating temperature for the $\mathrm{AE}$ sensor. Currently, the range of operating temperature this $\mathrm{AE}$ is $-35^{\circ} \mathrm{C}$ to $80^{\circ} \mathrm{C}$, which is not enough to cover the engine operating temperature. The engine operating temperature was occurring at $86^{\circ} \mathrm{C}$. This causes the $\mathrm{AE}$ sensor to become rapidly hot and will undoubtedly disrupt the data obtained.

\section{ACKNOWLEDGMENT}

\section{REFERENCES}

[1] Jamaludin, N. Inayatullah, O. Mohd Nor, M. J. and Mat, F. "Relationship between engine oil viscosity with age and temperature, Sains Malaysiana 40 (5), 2011, p: 509- 513

[2] Basu, A., Berndorfer, A., Buelna, C., Campbell, J., Ismail, K., Lin, Y., et al. (2000). Smart sensing of oil degradation and oil level measurements in gasoline engines. Report 2000-01-1366, Delphi Mexico Technical Center, SAE World Congress, Detroit, USA. Cash. W, Engine Lubrication Basics, 2012.

[3] Environmental Protection Agency (EPA). (1999). Oil life extension. Technical report, Environmental Protection Agency.

[4] Inayatullah,O. Ali, A. Jamaludin,N. and Mohd Nor, M. J. Application of Acoustic Emission Technique to Observer the Engine Oil's Viscosity. Proc. Of $2^{\text {nd }}$ International Conference on Instrumentation, Control and Automation, 2011, pp. 49-53. ISBN:978-1-4577-0/11 IEEE (Nov 15-17, 2011 - Bandung Indonesia).

[5] Hamel, M. Andali, A. and Mba, D. Employing Acoustic Emission for Monitoring Oil Film Regimes, ISSN 2075 -4442, UK, pp. 61-74, Lubricants 2013.

[6] Miller, K. R. Non-Destructive Testing Handbook Vol. 5- Acoustic Emission, American Society for Non-Destructive Testing, Columbus, 1987.

[7] Jamaludin, N. And Mohd Nor, M. J. Lubrication monitoring in a low speed bearing using acoustic emission technique, Proc. 15th lnt. Congress on Condition Monitoring and Diagnostic Engineering Management, Birmingham UK, pp. 521-527, 2002.

[8] Miettien, Condition Monitoring of Grease Lubricated Rolling Bearings by Acoustic Emission Measurements, PhD Thesis, Tampere University, Finland, 2000.

[9] Hafizi, M. Z. Nizwan, C. K. E. and Firdaus, D. M. A Study of Acoustic Emission Intensity Effect During Fuel Injector Fault, National Conference in Mechanical Engineering Research and Postgraduate Student, UMP, Malaysia,pp.495-501, 2010.

[10] Gill, J. D., Reuben R. L. and Steel,. J. A. 2000. A Study of Small HSDI Diesel Engine Fuel Injection Equipment Faults Using Acoustic Emission. Proc. EWGAE. 281286.

[11] El-Ghamry, M. H., R. L. Reuben, dan Steel J. A. 2003. The Development of Automated Pattern Recognition and Statistical Feature Isolation Techniques for the Diagnosis of Reciprocating Machinery Faults Using Acoustic Emission.Mechanical Systems and Signal Processing Journal. 17: 805-823.

[12] Azzoni P., Moro D. \& Rizzoni G. 1998.Time-Frequency Signal Analysis of the Acoustic Emission of Formula 1 Engines. IEEE Xplore, 441 -444.

[13] Fog, T. L., Brown, E. R., Hansen, H. S., Madsen, L. B., Rensen, P. S., Steel, J. A., Reuben, R. L. and Pedersen, P. S. 1998. Exhaust Valve Leakage Detection in Large Engine Diesel. Proceedings of the $11^{\text {th }}$ International Conference on Condition Monitoring and Diagnostic Engineering Management COMADAM. 1: 269278.

[14] Elamin, F., Gu, F. and Ball, A. D. Online Monitoring of Engine Oil Quality Based on AE Signal Analysis, Computing and Engineering Researchers Conference, pp. 116-123, Dec 2010.

[15] Fitch, J. Trouble-shooting Viscosity Excursion, Practising Oil Analysis, (5/2001).

[16] Li X.. 2002. A brief review: Acoustic Emission Method for Tool Wear Monitoring during Turning. International Journal of Machine Tools \& Manufacture. 42: 157-165.

[17] Nuawi M. Z., Abdullah S., Ismail A.R.; Zulkifli R., Zakaria M. K. \& Hussin M. F. H. 2008. A Study on Ultrasonic Signals Proce ssing Generated From Automobile Engine Block Using Statistical Analysis. WSEAS TRANSACTIONS on SIGNAL PRO CESSING, 4: $279-288$. 